\section{RECENT ADDITIONS TO THE ZOOLOGICAL SOCIETY'S GARDENS}

IN April last the total number of additions to the living collection of the Zoological Society of London was 124. Of these, twenty-one were born in the Gardens, fortyfour were acquired by presentation and fifty-two by purchase, while one was received in exchange, and six merely "on deposit." The "departures" during the same period, by death and otherwise, were ninety-one. Among the more noticeable additions were :-

I. A female of one of the smaller forms of Rusine deer, purchased by a dealer on the I3th of April, and stated to have been received from the Philippines. This animal is quite distinct in its small size and dark brown fur from any other member of the group now or lately in the Society's collection. If the assigned locality is correct it may probably belong to the Rusa deer of the Philippines, which was first named Cervus mariannus by Desmarest, as having been found living by the French naturalists during the voyage of the Uranie at the Marianne Islands. Here, however, it was stated to have been introduced from the Philippines. It would be very desirable to increase our knowledge of the deer of the Philippines. Probably there is more than one species that occurs there.

2. A Sooty Crow-Shrike (Strepera fuliginosa), purchased on the same day, is one of a peculiar group of Australian birds, of which the Society previously possessed examples belonging to two other species. These are all placed in the cages outside the "Parrot-house" which are devoted to the reception of the hardy species of crows (Corvidie) and their allies, and at the present moment contain examples of several other species of great interest, such as the yellow-billed chough of the Alps (Pyrrhocorax

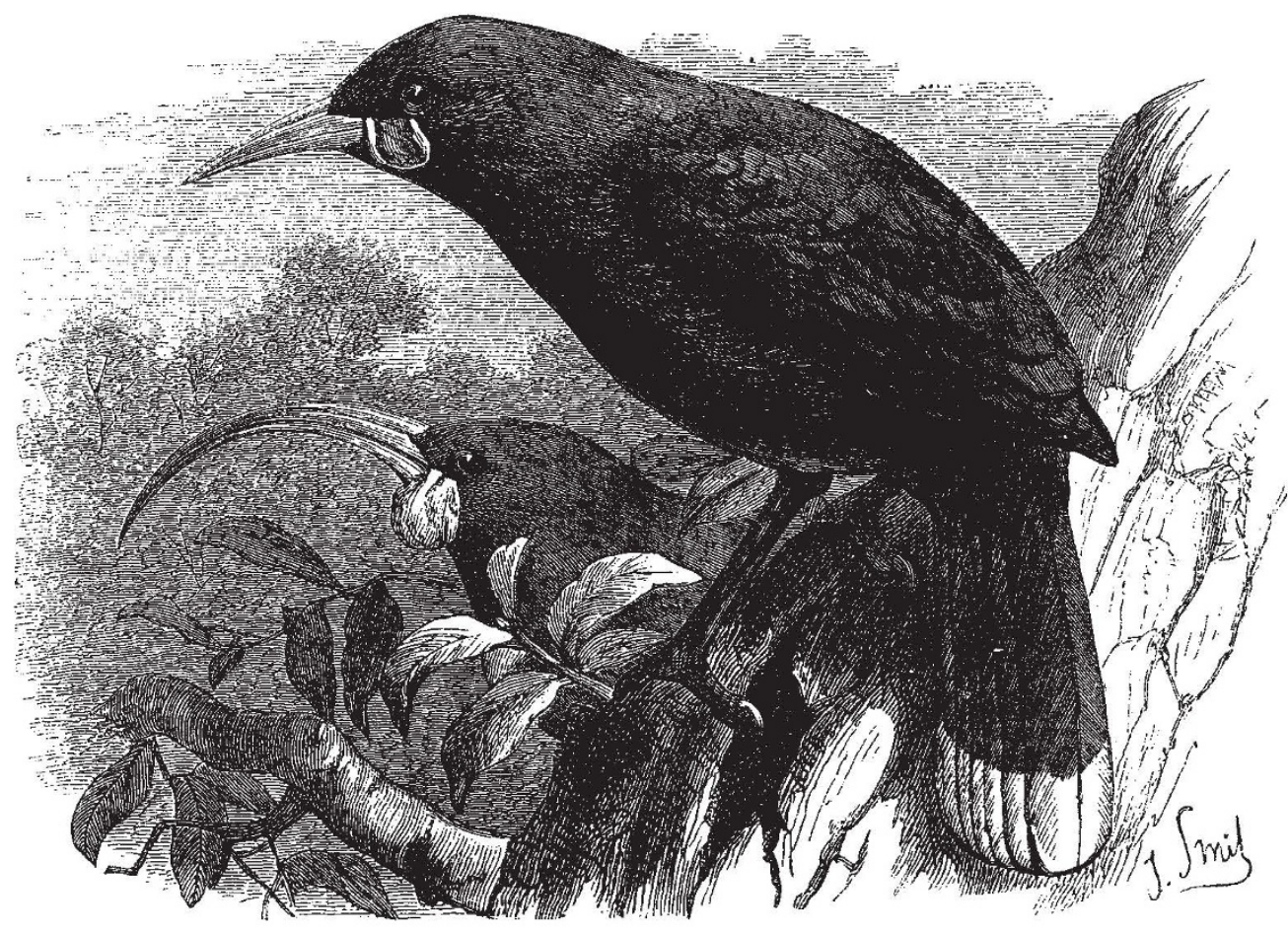

THE HUIA BIRD (Heteralocha gouldi)

alpinus), the chough of our own coasts (Fregilus graculus), the Chinese Jay-thrush (Garrulax sinensis), and the Australian crow (Corvus australis).

3. A Vulturine Guinea-Fowl (Numida vulturina) presented by Dr. John Kirk, C.M.Z.S., H.B.M. Acting Consul at Zanzibar.

For many years this remarkable Guinea-Fowl, which is peculiar for having the head entirely devoid of feathers, and for the long ornamental hackles surrounding the neck, was only known to naturalists from a single specimen, formerly in the United Service Museum. This was figured in Mr. Gould's "Icones Avium," but its exact locality was unknown. More recently, since the eastern coast of Africa has been more thoroughly explored, it has been discovered that this bird is by no means uncommon on the southern part of the Somali coast, and in the adjacent parts of continental Africa. Dr. John Kirk, the well-known companion of Dr. Livingstone in the Zambesi expcdition, who has been lately resident at Zanzibar, as acting Consul, has communicated several notices upon this Guinea-fowl to the Zoological Society, of which he is an active correspondent. In one of his letters he says that "it seems to be common at Lamoo, a port situated on the east coast of Africa, in about $2^{\circ} \mathrm{S}$. lat. The officers of H.M.S. Syria, when lately there, saw several in the market, but used them for the table, not being aware of their great rarity." More recently Dr. Kirk succeeded in securing for the aviaries of the Society the present female example of the species. This fine bird was procured at Brava on the southern part of the Somali coast, just to the north of the equator, and was conveyed, along with a collection of other animals presented to the Zoological Society by Dr. Kirk, in the steamer, Malta, through the Suez Canal to Marseilles, under the kind care of Captain Mackenzie.

4. A jackal, stated to have been brought from the River Fernand Vas, south of the Gaboon, and to be the animal referred to in Du Chaillu's well-known "Explo- 
rations and Adventures in Equatorial Africa" (p. 243), in the following passage :--

"Before we got to town again, I shot a mboyo, a very shy animal of the wolf kind, with long yellowish hair, and straight ears. I have often watched these beasts surrounding and chasing small game for themselves. The drove runs very well together, and as their policy is to run round and round, they soon bewilder, tire out, and capture any animal of moderate endurance."

Such is M. Du Chaillu's fragmentary notice of this animal, of which, however, he does not appear to have sent home specimens. After endeavouring in vain to find a name for this distinctly-marked species of Canis, which is readily recognisable by the black and white stripes along the flank, and the long black tail with a black termination, I proposed at the meeting of the Zoological Society, on May 12th, to call it Canis lateralis. Dr. Peters, however, has since suggested to me that it may be the Canis adustus of Sundeval, and this identification is probably correct, although our example does not agree very well with Sundeval's description. I may also remark that there is no example of Canis adustus in the British Museum, and that, without the aid of specimens, the differentiation of the various species of Canis is by no means an easy task.

In the month of May the number of additions to the Society's collection of living animals was still more numerous than in April, amounting altogether to 200. Of these fifty-four were received as presents and eighty-three acquired by purchase; forty-five were bred in the gardens and eighteen were deposited for safe custody. The number of departures in May, by death or otherwise, was seventy-five.

Amongst the 200 acquisitions in May were several of great interest, viz. :-

I. A male deer, forwarded to the Gardens from Singapore by order of H.R.H. the Duke of Edinburgh. 'This is quite different from any other deer yet obtained living

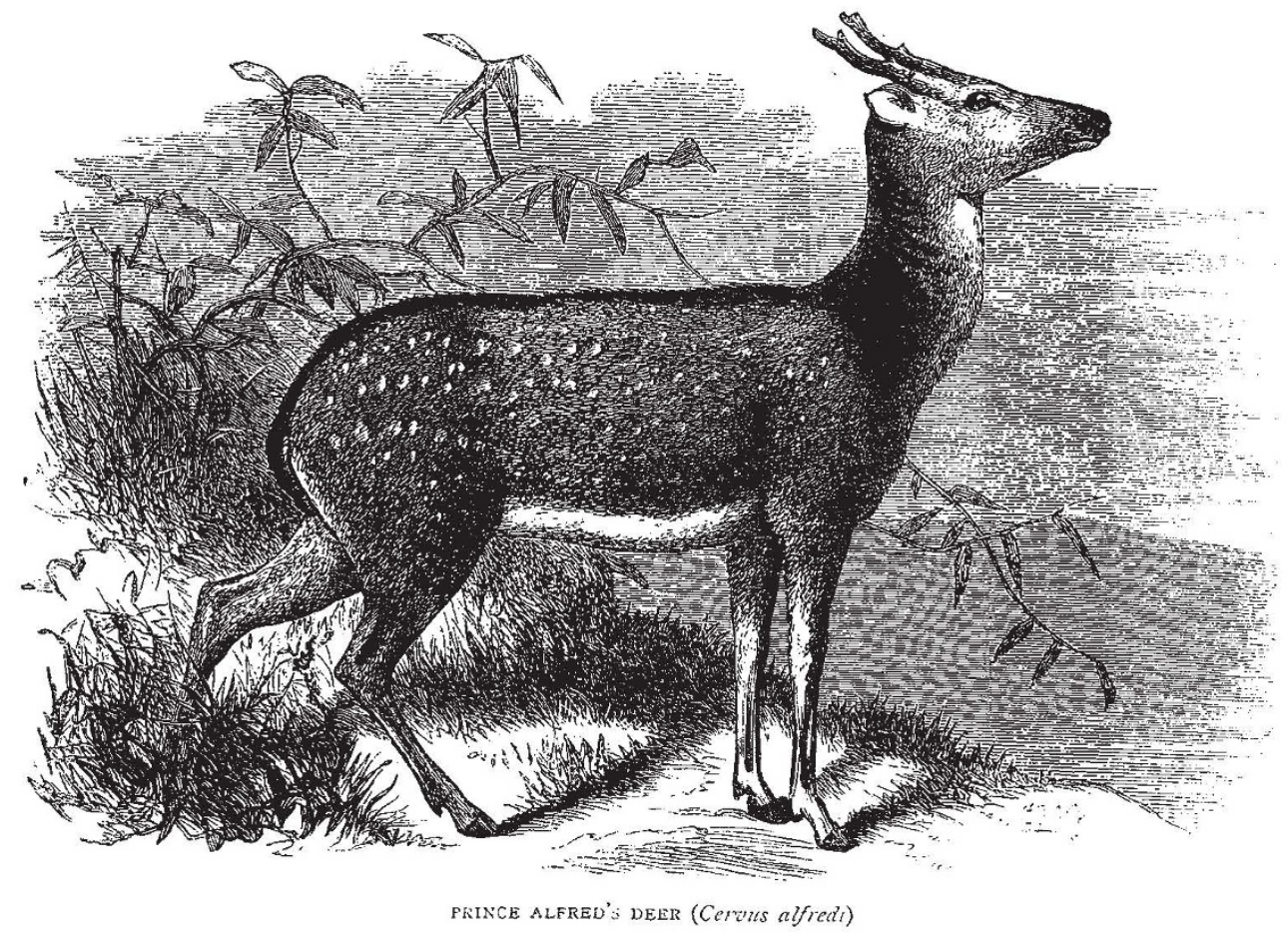

by the Zoological Society. It is obviously allied to the axis or spotted deer of continental India, and may be the Malayan form of that species. It differs, however, in its smaller size and smaller ears, and in the dark coffee-brown colour of the fur. I have not been able to find any designation applicable to it, and, at a recent meeting of the Zoological Society, have proposed to call it Cervuts alfredi, after the Prince, who has transmitted the present individual to us.

2. Thrce examples of the crested or bladder-nosed seal of the Arctic Seas (Cystophora cristata), purchased May 5 , out of a whaling vessel, which brought them into Dundee. These are the first examples of this seal that have reached the Society's gardens alive, and are of much interest, as making us acquainted with the external form of a very distinct genus of the Phocidce. The bladderlike excrescence on the forehead, which attains an extraordinary devclopment in the adult male, is but very slightly shown in these young animals, but a look in the mouth at once shows their difference from the typical seals of the genus Phoca.

3.: A huia-bird (Heteralocha gouldi), from New Zealand, purchased May I 8th. This bird is remarkable for the great difference in the shape of the bill between the two sexes, as will be readily understood by reference to the accompanying illustration, in which the short-billed individual is the male and the long-billed the female. The figure of the male is taken from the Zoological Society" specimen, the head of the female is copied from Mr. Gould's plate of this species in the "Birds of Australia." Such a divergence in the structure of the beak of the two sexes is very uncommon and scarcely to be paralleled in the class of birds. It is difficult to guess at the reason of it, or to explain it on Darwinian or any other principles. The story is that the male employs his stronger instrument to hew away the wood that covers the grub, and the female her more delicate organ to extract the precious morsel. Unfortunately, we have as yet only one sca of 
this bird living in the Society's Gardens, but it is so far certain that our male is evidently very fond of grubs, and will search for them with eagerness in rotten wood. He does not, however, seem obliged to wait for a female of his own species to extract them when discovered, but picks them out for himself. A somewhat parallel case of difference of the bill in the male and female occurs in the humming-birds of the genus Grypus.*

4. A Tuatera lizard (Sphenodon punctatum), purchased May zoth.

This not very attractive-looking lizard is really one of the most extraordinary reptiles now known to exist on the world's surface. In several important particulars of structure it differs from every other known saurian, insomuch that Dr. Günther, who has published an elaborate memoir on its anatomy, ${ }^{*}$ has proposed to constitute it of itself a distinct order of reptilia, equal in systematic rank to the ophidians and saurians. It differs from all the known members of the latter order in having the quadrate bone firmly anchylosed to the skull, and in the entire absence of an intromittent copulatory organ. The vertebra are amphicælian, as in the Geckoid lizards. Dr. Gray first described and figured this reptile under the name Hatteria (!) punctaia, and it has been so generally designated until lately, when it was most fortunately discovered that the generic term Sphenodon had been previousiy applied to a specimen of its skull in the museum of the College of Surgeons. It has thus become possible not to be obliged to employ so vile and barbarous a term as Hatteria for the name of this important animal. Dr. Günther, when he wrote his memoir, supposed that this reptile was extinct or nearly so. But one living example has reached England since that date, and more than one, I believe, in spirits. From an article published by Dr. Bennett, of Sydney, in the Morning Herald of that city, it appears that so recently as December 1851 , this lizard was abundant in one of the islands in the Bay of Plenty, on the north coast of New Zealand. The island in question is one of four small volcanic islands, distant about eight miles from the coast, and situated opposite to the mouth of the Wakatane river. A party of officers, who visited it upon the occasion referred to, are stated to have collected in half an hour nearly forty of these lizards of different sizes, varying from two feet long to three inches. They stated that the island seemed to be swarming with them, and with another lizard called the moko-moko (Tiliqua zeelandica). In the day-time these lizards are seen basking themselves in the sun on the bare rocks. Noon is therefore the best time to visit the islands. It is stated that there are four small islands, on two of which Tuateras are found.

I mention this fact in case it should be within the power of any of the Antipodean readers of NATURE to visit these islands, and obtain examples of this reptile. For although the British Museum has a good supply of specimens of it, yet the animal is a great desideratum elsewhere, and I believe there are no examples of Sphenodon in any of the continental collections.

P. L. S.

\section{NOTES}

THE honorary degree of D.C.L. has been conferred, at the recent Commemoration, by the University of Oxford on the following scientific men:-Sir William George Armstrong, C.B.; Sir James Alderson, M.D., President of the Royal College of Physicians ; John P. Gassiot, Vice-President of the Royal Society ; Charles W. Siemens, F.R.S.; James Fergusson, F.R.S.; Sir J. Kay-Shuttleworth, Bart., the Rev Henry Moseley, M.A., F.R.S., Canon of Bristol; Professor Hermann Helmholtz; George Edward Paget, M.D., President of the General Medical Council ; Edward Frankland, F.R.S.; Henry Bence Jones,

* See Gould's Monograph of the Trochilida, Introduction, p. xxxvi.

$t$ Phil. Trans. 8667 , p. 595.
M.D., F.R.S.; Warren De La Rue, Vice-President of the Royal Society; William Ituggins, F.R.S., Secretary to the Royal Astronomical Society. The name of Charles Darwin, F.R.S., would have been included in the foregoing list (as stated in our last number) but he writes that his health is such "that he could not withstand the fatigue and excitement of receiving an honorary degree." We understand that Prof. Helmholtz has also been prevented from attending. There is a rumour that Science would have been even more brilliantly represented If the degree were the simple thing it is often supposed to be. It really stamps, it seems, a judicious mixture of celebrity and orthodoxy ; e.g., either much orthodoxy and a little celebrity, or a little orthodoxy and much celebrity, will qualify, but a dash of orthodoxy is de rigueur. The imprimatur, therefore, is of double value. In the present case, for instance, it is proclaimed to the world that Mr. Darwin, for example, is not only Mr. Darwin, but that Dr. Pusey, and others even more skilled in heresy than he, consider him orthodox. On the whole we should prefer the abolition of tests even here, and one has only to go to Oxford and watch the present scientific activity, the magnificent museums and laboratories which are growing or have grown, to predict that the Oxford of a few years hence will be of the same opinion.

Mentings of the Royal Commission on Scientific Instruction and the Advancement of Science have been held at 6 , Old Palace Yard, S.W., on the $14^{t h}$, I $5^{\text {th, }}$ I 7 th, and 2 rst of this month. Present:-The Duke of Devonshire, K.G.; the Marquis of Lansdowne; Sir John Lubbock, Bart., M.P., F.R.S.; Sir J. P. Kay Shuttleworth, Bart.; Mr. B. Samuelson, M.P.; Dr. Sharpey, Sec., R.S.; Prof. Huxley, F.R.S.; Dr. W. A. Miller, Treas., R.S.; Prof. Stokes, Sec. R.S.; and the Secretary, Mr. J. Norman Lockyer, F.R.S.

Mr. E. J. Stone, F.R.S., first assistant at the Greenwich Observatory, has been appointed Astronomer at the Cape of Good Hope. This appointment will be hailed with the liveliest satisfaction by all scientific men, and we may hope that the fine Observatory there may soon take high rank among similar establishments.

THE examiners for honours in the Natural Science School at the University of Oxford, viz., Henry J. S. Smith, Edward Chapman, and Joseph F. Payne, have made the following award:-Class I. Walter William Fisher, Postmaster of Merton College; Edwin Harding Lendon, Gunsley Exhibitioner, University College; Charles Samuel Taylor, Commoner of Merton College. Class 2. John Fleming Hartley, Commoner of Brasenose College. Class 3. John Richardson Burrow, Thanet Exhibitioner of Queen's College. Class 4. Nil.

WE hear with great satisfaction that the Government of India has ordered the adoption of the metric system of weights and measures.

A NEW Astronomical Observatory has been established by the Government of the Argentine Republic in South America, to be erected at Cordova, about the middle of the continent, on the margin of the Pampas, in lat. $31^{\circ}{ }^{\circ} \mathrm{S}$. Dr. B. A. Gould has been invited to organise it, and is going out for the special purpose of extending through the southern hemisphere the system of zones, which Bessel and Argelander have already carried from the north pole as far as $30^{\circ} \mathrm{S}$. He hopes also to obtain some photometric determinations of the principal southern stars. The undertaking has been instituted and carried out entirely by the Government of the Argentine Republic, at the instance of the President, M. Sarmiento, and of Dr. Avellaneda, the Minister of Public Instruction; but the various scientific institutions of the United States have aided the expedition greatly by loans of important and valuable instruments ; and Dr. Gould expresses his obligation to the Coast Survey, the "American Nautical Almanac," 